Research Article

\title{
Experimental Study on the Creep Behavior of Red Sandstone under Low Temperatures
}

\author{
Yongjun Song, Leitao Zhang (D), Huimin Yang, Jianxi Ren, and Yongxin Che \\ School of Architecture and Civil Engineering, Xi'an University of Science and Technology, Xi'an 710054, China \\ Correspondence should be addressed to Leitao Zhang; zhanglt95@163.com
}

Received 1 June 2019; Revised 25 August 2019; Accepted 6 September 2019; Published 9 October 2019

Academic Editor: Fan Gu

Copyright (C) 2019 Yongjun Song et al. This is an open access article distributed under the Creative Commons Attribution License, which permits unrestricted use, distribution, and reproduction in any medium, provided the original work is properly cited.

In cold regions, the deformation characteristics and long-term mechanical properties of rocks under low-temperature conditions are considerably different from those in other regions. To study the deformation characteristics and long-term mechanical properties of rocks in a low-temperature environment and the effect of different temperatures, we perform a multilevel loadingunloading uniaxial creep test on red sandstone samples and obtain the creep curves at different temperatures $\left(20^{\circ} \mathrm{C},-10^{\circ} \mathrm{C}\right.$, and $-20^{\circ} \mathrm{C}$ ). The results demonstrate that the total strain at each temperature can be divided into instantaneous and creep strains; the instantaneous strain includes instantaneous elastic and plastic strains, and the creep strain includes viscoelastic and viscoplastic strains. Temperature has a significant effect on the deformation properties of red sandstone. A decrease in temperature reduces the instantaneous and creep deformations of the rocks at all levels of stress. In addition, a decrease in temperature exponentially attenuates the total creep and viscoplastic strains of the rocks. $0^{\circ} \mathrm{C}$ is a critical point for the reduction of the total creep and viscoplastic strains of the rocks. When the temperature is greater than $0^{\circ} \mathrm{C}$, the total creep and viscoplastic strains of the rocks decrease rapidly and linearly with decrease in temperature; however, when the temperature is less than $0^{\circ} \mathrm{C}$, the decrease in the total creep and viscoplastic strains of the rocks is slow. The steady-state creep rate of the rock samples decreases with decrease in temperature, whereas the creep duration increases with decrease in temperature, especially in the case of the accelerated creep stage. The accelerated creep durations of the rock samples $\mathrm{S} 4\left(20^{\circ} \mathrm{C}\right)$ and $\mathrm{S} 7\left(-10^{\circ} \mathrm{C}\right)$ are $0.07 \mathrm{~h}$ and $0.23 \mathrm{~h}$, respectively.

\section{Introduction}

Rocks, natural substances formed by a geological process, are one of the most common substances on the surface of the earth [1]. With the development of economic activities, increasingly more large-scale rock mass projects such as cold-zone tunnels, coal mine construction, and low-temperature underground storage facilities for liquefied natural gas are being constructed in cold regions; these involve different long-term mechanical behaviors of rocks in lowtemperature environments. The majority of the coal resources in the western region of China are covered with a thick water-rich Cretaceous soft rock stratum; hence, mine construction is undertaken primarily using a freezing method. Numerous researchers have studied the deformation and mechanical properties of rocks under lowtemperature conditions. Inada and Yokota [2] conducted uniaxial compression and tensile tests on granite and andesite under different temperatures in the range of $-160^{\circ} \mathrm{C}$ to $20^{\circ} \mathrm{C}$, and they studied the influence of temperature changes on strength of rocks. The results revealed that rock strength increases with decrease in temperature. Aoki et al. [3] performed uniaxial compression and tensile tests on granite and rhyolite under different temperatures in the range of $-160^{\circ} \mathrm{C}$ to $15^{\circ} \mathrm{C}$, and they reported that the elastic modulus of rocks increases with decrease in temperature. Yamabe and Neaupanek [4] tested basic physical properties of rocks such as the compressive strength and elastic modulus under low-temperature conditions. The strength and elastic modulus of frozen rocks were found to be greater than those of unfrozen rocks; the compressive strength and elastic modulus increased with decrease in temperature. Jiang et al. [5] conducted uniaxial compression tests on saturated sandstone under different temperatures in the range of $-30^{\circ} \mathrm{C}$ to $-5^{\circ} \mathrm{C}$ to study the effects of low temperature on the frost heave mechanism and the mechanical 
properties of rock mass. The test results revealed that freezing a rock can significantly improve its internal structure and strength characteristics. Park et al. [6] studied the relationship between thermophysical parameters and temperature of Korean granite and sandstone under low temperatures. $\mathrm{Xu}$ et al. [7] conducted uniaxial and triaxial compression tests on red sandstone and shale under disparate freezing temperatures and water states (saturated and dry). The results revealed that the uniaxial compressive strength and elastic modulus of these two types of rocks typically increase when the temperature decreases from $20^{\circ} \mathrm{C}$ to $-20^{\circ} \mathrm{C}$. Tang et al. [8] performed uniaxial and triaxial compression tests on granite under different freezing temperatures $\left(-10^{\circ} \mathrm{C}\right.$ to $\left.-50^{\circ} \mathrm{C}\right)$ and moisture conditions (saturated and dry). The tests revealed that rock strength increases nonlinearly with decrease in temperature; however, there is a threshold point (approximately $-40^{\circ} \mathrm{C}$ ) at which the strength of granite tends to stabilize. Xi et al. [9] conducted uniaxial and triaxial compression tests on saturated sandy mudstone under different confining pressures and temperatures $\left(-30^{\circ} \mathrm{C}\right.$ to $\left.20^{\circ} \mathrm{C}\right)$ to analyze the effects of low temperature on basic mechanical parameters of sandy mudstone. The abovementioned studies have made important contributions to the understanding of rock mechanics under low-temperature conditions. A majority of these studies address the instantaneous deformation and mechanical properties or rock failure mechanism of rocks under low-temperature conditions.

Creep is one of the crucial mechanical properties of rocks. The creep properties of rocks are distinctly different based on lithological and environmental differences, and they are closely related to the safety and long-term stability of rock mass engineering. Many studies have been conducted based on rock creep [10-20]. However, the effects of temperature on the creep properties of rocks have only been studied for high temperatures. Chen et al. [21, 22] used the MTS815 rock mechanics test system to study the effects of different temperatures on the creep properties of Beishan granite. The results showed that when the temperature is higher than $90^{\circ} \mathrm{C}$, the creep deformation increases with increase in temperature. Heap et al. [23] conducted triaxial creep tests on sandstone to study the effect of different temperatures $\left(20^{\circ} \mathrm{C}\right.$ to $\left.75^{\circ} \mathrm{C}\right)$ on the rock creep rate; the study concluded that temperature is the main influencing factor of the rock creep rate with a depth in the shallow crust. Lu and Wang [24] conducted creep tests on coal measures mudstone to study the effects of temperature on the long-term mechanical properties of mudstone. As the temperature increased, the increase in the creep-strain rate of the rock with the change in stress level was more apparent. Rybacki et al. [25] performed creep tests on the Dotternhausen Posidonia Shale under different temperatures $\left(50^{\circ} \mathrm{C}\right.$ to $\left.200^{\circ} \mathrm{C}\right)$ and studied the effect of temperature on the rock creep properties. Wang et al. [26] conducted a high-temperature high-pressure rock triaxial test on granite samples and studied the creep deformation under high temperatures and pressures. The results showed that the creep properties of granite increased with increase in temperature. Only a small number of studies have focused on the creep properties of rocks under low temperatures. Li et al. [27] performed triaxial creep tests on Cretaceous frozen soft rock at temperatures of $-10^{\circ} \mathrm{C}$ and $-8^{\circ} \mathrm{C}$ and proposed a nonlinear viscoelasticplastic creep constitutive model for frozen soft rock. Shan et al. $[28,29]$ conducted uniaxial creep tests on frozen red sandstone at $-10^{\circ} \mathrm{C}$ and proposed a theoretical model based on the creep properties of rock. Further systematic study of creep properties of rocks at low temperatures is urgently required.

In this study, a multilevel loading-unloading uniaxial creep test is performed on saturated red sandstone under different temperatures. The creep properties of the rock and the effect of temperature on it are analyzed. This study provides a reliable basis for the long-term stability analysis of rock mass engineering in cold regions.

\section{Experiments}

2.1. Specimen Preparation. The red sandstone specimens in this study were collected from the Dafosi Coal Mine that is located in the midwest Binchang mining area, Jurassic Coalfield, Huanglong, Shaanxi Province. The rock formations are primarily weak medium-fine sandstones with large thickness. The rock samples were cut into standard cylindrical specimens (Figure 1) with a length and diameter of $100 \mathrm{~mm}$ and $50 \mathrm{~mm}$, respectively.

The rock specimens were placed in an oven at $105^{\circ} \mathrm{C}$ for $48 \mathrm{~h}$ and weighed to determine their dry density. An ultrasonic tester was used to measure the wave velocity of the dried rock samples, and the wave velocity of each rock sample was obtained. Then, the specimens were soaked in water for $48 \mathrm{~h}$ and weighed in air and water to determine their saturated water content and porosity. Rock samples with similar wave velocity and dry density values were grouped together. The rock samples were divided into four groups: one group was for the conventional uniaxial compression test, and the other three groups were for the creep test. The average physical parameters of the red sandstone are listed in Table 1.

2.2. Testing Procedure. Creep tests were performed using the servo-hydraulic rock mechanics testing system (MTS810) in the State Key Laboratory of Frozen Soil Engineering of the Northwest Institute of Eco-Environment and Resources at the Chinese Academy of Sciences. The rock mechanics test system is shown in Figure 2. The maximum axial load of the testing machine is $250 \mathrm{kN}$, and the temperature error of the pressure chamber does not exceed $\pm 0.5^{\circ} \mathrm{C}$.

To prevent the loss of water in saturated rock samples during the entire test process, the samples were completely smeared with Vaseline and sealed with latex. The prepared rock specimens were placed in a box at a low temperature with a cooling rate of $0.02^{\circ} \mathrm{C} / \mathrm{min}$. They were kept in the box for $24 \mathrm{~h}$ to ensure that their internal temperature achieved the specified temperature. Simultaneously, the temperature of the pressure chamber in the testing machine (MTS810) was reduced to the specified temperature. Then, the rock 


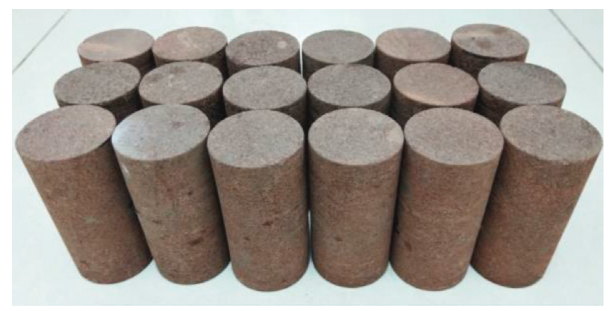

Figure 1: Red sandstone specimens.

TABle 1: Average physical and mechanical parameters of red sandstone.

\begin{tabular}{|c|c|c|c|c|c|}
\hline P-wave velocity $(\mathrm{m} / \mathrm{s})$ & $\begin{array}{c}\text { Dry density } \\
\left(\mathrm{g} / \mathrm{cm}^{3}\right)\end{array}$ & $\begin{array}{l}\text { Saturated density } \\
\left(\mathrm{g} / \mathrm{cm}^{3}\right)\end{array}$ & Saturated water content (\%) & Porosity (\%) & Uniaxial compressive strength $(\mathrm{MPa})$ \\
\hline 1076 & 2.23 & 2.34 & 4.86 & 9.71 & 7.87 \\
\hline
\end{tabular}

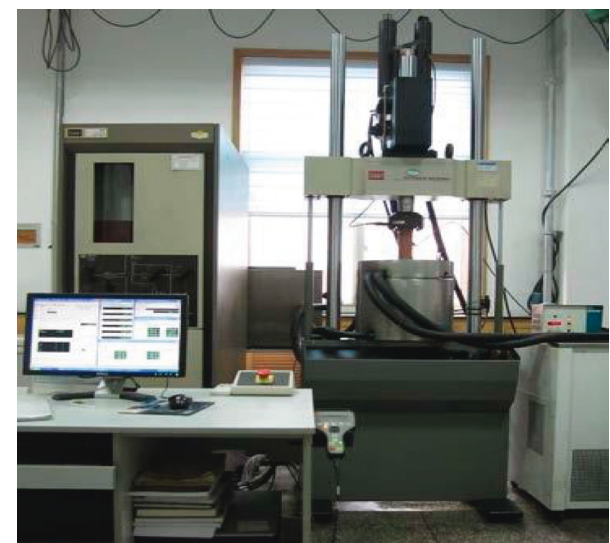

Figure 2: Testing system for rocks at low temperatures.

specimens were removed from the box and placed in the pressure chamber of MTS810 immediately after the freezing time met the specified test requirements. They were kept in the pressure chamber for $2 \mathrm{~h}$ to stabilize the temperature following the transportation.

First, conventional uniaxial compression tests were conducted to derive the peak uniaxial compressive strength. The results determined the stress levels to be used in the creep tests (Table 1). Then, the creep tests were performed under multilevel loading-unloading cycles as shown in Figure 3.

The load was increased at a rate of $0.01 \mathrm{MPa} / \mathrm{s}$ to achieve the target stress level; this level was maintained steadily until the rate of deformation stabilized. Then, the load was decreased at a rate of $0.03 \mathrm{MPa} / \mathrm{s}$ until it reached 0 , where it was maintained until the completion of the strain recovery. The next stage began by following the same sequence. To analyze the stability of the frozen rock mass in a coal mine shaft according to the temperature for wellbore freezing $\left(-20^{\circ} \mathrm{C}\right)$ and the average temperature of a frozen wall $\left(-8.84^{\circ} \mathrm{C}\right)$, the test temperatures were set to $20^{\circ} \mathrm{C},-10^{\circ} \mathrm{C}$, and $-20^{\circ} \mathrm{C}$, where $20^{\circ} \mathrm{C}$ represented the ambient-temperature control group. Three specimens were tested simultaneously at the same temperature to acquire the representative creep curves.

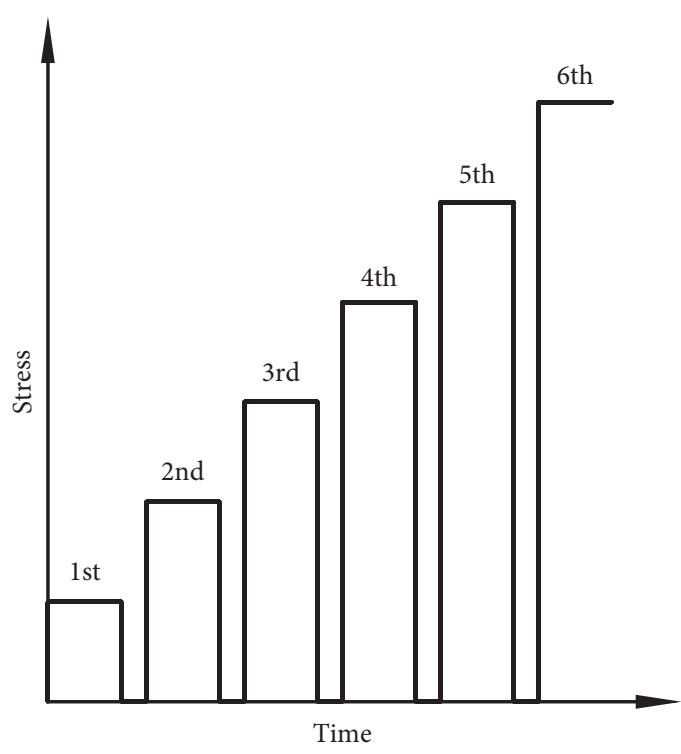

FIGURE 3: Multilevel loading-unloading process for uniaxial creep testing.

\section{Test Data Processing}

Figure 4 presents a representative creep curve under a loading-unloading cycle. The total strain of the rock consists of the instantaneous strain $\varepsilon_{\mathrm{m}}$ and creep strain $\varepsilon_{\mathrm{c}}[30,31]$ :

$$
\varepsilon=\varepsilon_{\mathrm{m}}+\varepsilon_{\mathrm{c}} \text {. }
$$

The instantaneous strain $\varepsilon_{\mathrm{m}}^{(i)}$ under a stress level $\sigma_{i}$ consists of the instantaneous elastic strain $\varepsilon_{\text {me }}^{(i)}$ and instantaneous plastic strain increment $\Delta \varepsilon_{\mathrm{mp}}^{(i)}$ that are produced by the stress increment $\Delta \sigma_{i}\left(\Delta \sigma_{i}=\sigma_{i}-\sigma_{i-1}\right)$. According to Hooke's law, the instantaneous elastic strain recovers completely after unloading. Therefore, the instantaneous elastic strain $\varepsilon_{\text {me }}^{(i)}$ under a stress level $\sigma_{i}$ must be equal to the instantaneous elastic recovery strain $\varepsilon_{\mathrm{mr}}^{(i)}$ after unloading. Hence, the equation for $\Delta \varepsilon_{\mathrm{mp}}^{(i)}$ is

$$
\Delta \varepsilon_{\mathrm{mp}}^{(i)}=\varepsilon_{\mathrm{m}}^{(i)}-\varepsilon_{\mathrm{me}}^{(i)}=\varepsilon_{\mathrm{m}}^{(i)}-\varepsilon_{\mathrm{mr}}^{(i)} .
$$




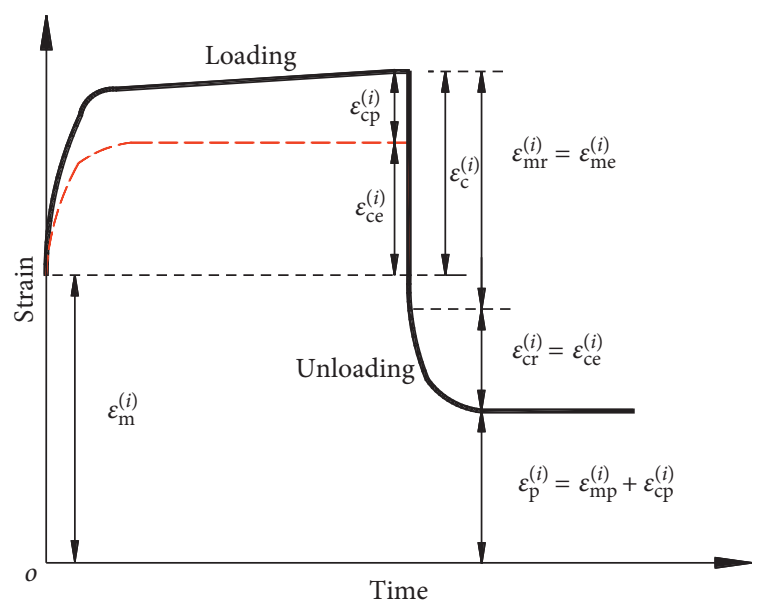

FIgURE 4: Representative rheological curve under loading and unloading.

In equation (2), the instantaneous elastic recovery strain $\varepsilon_{\mathrm{mr}}^{(i)}$ can be derived from the instantaneous elastic recovery curve after unloading, and the instantaneous strain $\varepsilon_{\mathrm{m}}^{(i)} \mathrm{can}$ be derived from the instantaneous loading curve. Therefore, the instantaneous plastic strain increment $\Delta \varepsilon_{\mathrm{mp}}^{(i)}$ can be acquired using equation (2).

Similarly, the creep strain $\varepsilon_{\mathrm{c}}^{(i)}$ under a stress level $\sigma_{i}$ consists of two parts: the viscoelastic strain $\varepsilon_{\mathrm{ce}}^{(i)}$ and viscoplastic strain increment $\Delta \varepsilon_{\mathrm{cp}}^{(i)}$ that are produced by the stress increment $\Delta \sigma_{i}\left(\Delta \sigma_{i}=\sigma_{i}-\sigma_{i-1}\right)$. According to the complete reversibility of viscoelastic deformation, it can be determined that the viscoelastic strain $\varepsilon_{\mathrm{ce}}^{(i)}$ of rock specimens under a certain stress level must be equal to the hysteresis elastic recovery strain $\varepsilon_{\mathrm{cr}}^{(i)}$. Hence, the equation for $\Delta \varepsilon_{\mathrm{mp}}^{(i)}$ is

$$
\Delta \varepsilon_{\mathrm{cp}}^{(i)}=\varepsilon_{\mathrm{c}}^{(i)}-\varepsilon_{\mathrm{ce}}^{(i)}=\varepsilon_{\mathrm{c}}^{(i)}-\varepsilon_{\mathrm{cr}}^{(i)} .
$$

In equation (3), the hysteresis elastic recovery strain $\varepsilon_{c r}^{(i)}$ can be derived from the hysteresis elastic recovery curve after unloading. The creep strain $\varepsilon_{c}^{(i)}$ can be derived from the creep-strain curve. Therefore, the viscoplastic strain increment $\Delta \varepsilon_{\mathrm{cp}}^{(i)}$ can be acquired using equation (3).

The instantaneous plastic and viscoplastic strains under a stress level $\sigma_{n}$ are defined as follows:

$$
\begin{aligned}
& \varepsilon_{\mathrm{mp}}^{(n)}=\sum_{i=1}^{n} \Delta \varepsilon_{\mathrm{mp}}^{(i)}, \\
& \varepsilon_{\mathrm{cp}}^{(n)}=\sum_{i=1}^{n} \Delta \varepsilon_{\mathrm{cp}}^{(i)} .
\end{aligned}
$$

Therefore, the instantaneous strain $\varepsilon_{\mathrm{m}}^{(n)}$ and creep strain $\varepsilon_{c}^{(n)}$ of a rock specimen under a stress level $\sigma_{n}$ can be calculated using the following formulas:

$$
\begin{aligned}
& \varepsilon_{\mathrm{m}}^{(n)}=\varepsilon_{\mathrm{me}}^{(n)}+\varepsilon_{\mathrm{mp}}^{(n)}=\varepsilon_{\mathrm{me}}^{(n)}+\sum_{i=1}^{n} \Delta \varepsilon_{\mathrm{mp}}^{(i)}, \\
& \varepsilon_{\mathrm{c}}^{(n)}=\varepsilon_{\mathrm{ce}}^{(n)}+\varepsilon_{\mathrm{cp}}^{(n)}=\varepsilon_{\mathrm{ce}}^{(n)}+\sum_{i=1}^{n} \Delta \varepsilon_{\mathrm{cp}}^{(i)} .
\end{aligned}
$$

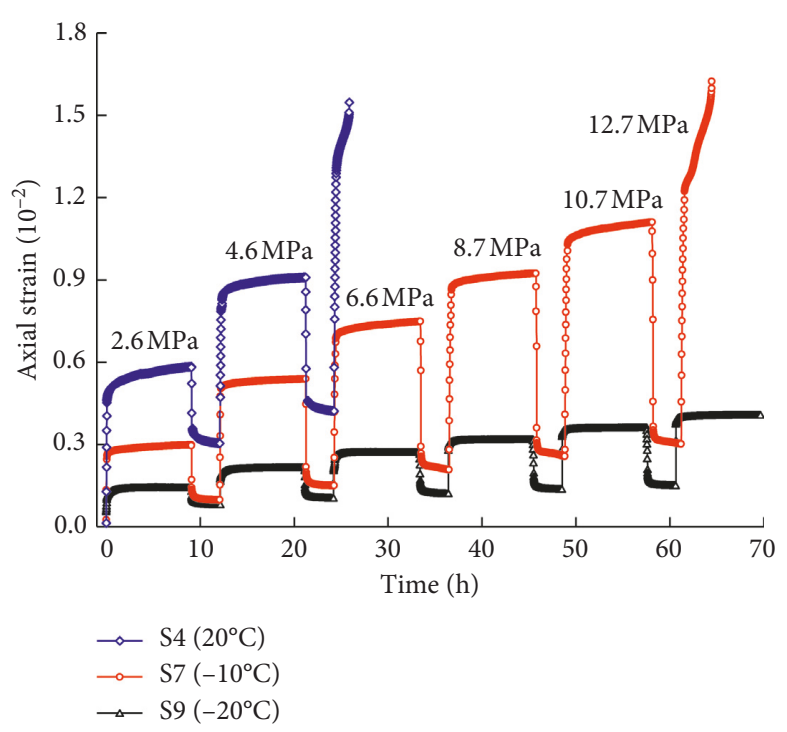

FIgURE 5: Uniaxial loading-unloading creep curves at different temperatures.

\section{Experimental Results}

Figure 5 presents the uniaxial creep test curves of the red sandstone specimens under loading and unloading cycles at temperatures of $20^{\circ} \mathrm{C},-10^{\circ} \mathrm{C}$, and $-20^{\circ} \mathrm{C}$. It is evident that red sandstone exhibits three typical stages of creep: attenuation, steady-state, and accelerated creeps. The rock specimens exhibit attenuation and steady-state creeps under all stress levels prior to creep failure. Furthermore, they exhibit attenuation, steadystate, and accelerated creeps under the final loading cycle.

Temperature has a significant effect on the deformation properties of red sandstone. The instantaneous strain and creep strain are significantly reduced by low temperatures. For example, when the stress level is $4.6 \mathrm{MPa}$, the instantaneous strains of specimens $\mathrm{S} 4\left(20^{\circ} \mathrm{C}\right), \mathrm{S} 7\left(-10^{\circ} \mathrm{C}\right)$, and S9 $\left(-20^{\circ} \mathrm{C}\right)$ are $7.074 \times 10^{-3}, 4.960 \times 10^{-3}$, and $1.650 \times 10^{-3}$, respectively; reductions of $29.88 \%$ and $66.73 \%$ are reported for cold specimens S7 and S9, respectively. The creep strains are $2.02 \times 10^{-3}, 4.74 \times 10^{-4}$, and $4.30 \times 10^{-4}$ for specimens $S 4$, S7, and S9, respectively; reductions of $76.53 \%$ and $9.28 \%$ are reported for cold specimens S7 and S9, respectively.

Creep failure stress increases drastically with decrease in temperature. For example, specimen S4 experienced attenuation creep, steady-state creep, and accelerated creep; then, it ruptured at the third stress level with a creep failure stress of 6.6 MPa. Specimen S7 failed at the sixth stress level with a creep failure stress of $12.7 \mathrm{MPa}$. Specimen S9 only experienced two stages of creep (attenuation creep and steady-state creep) at the sixth stress level; it did not exhibit accelerated creep or any indication of failure.

4.1. Instantaneous Strain. According to the aforementioned process of loading and unloading, the instantaneous strain of rock under all stress levels is composed of instantaneous elastic strain and instantaneous plastic strain based on the loading history. Figure 6 presents the curves of the instantaneous strain and stress levels at temperatures of $20^{\circ} \mathrm{C}$, 


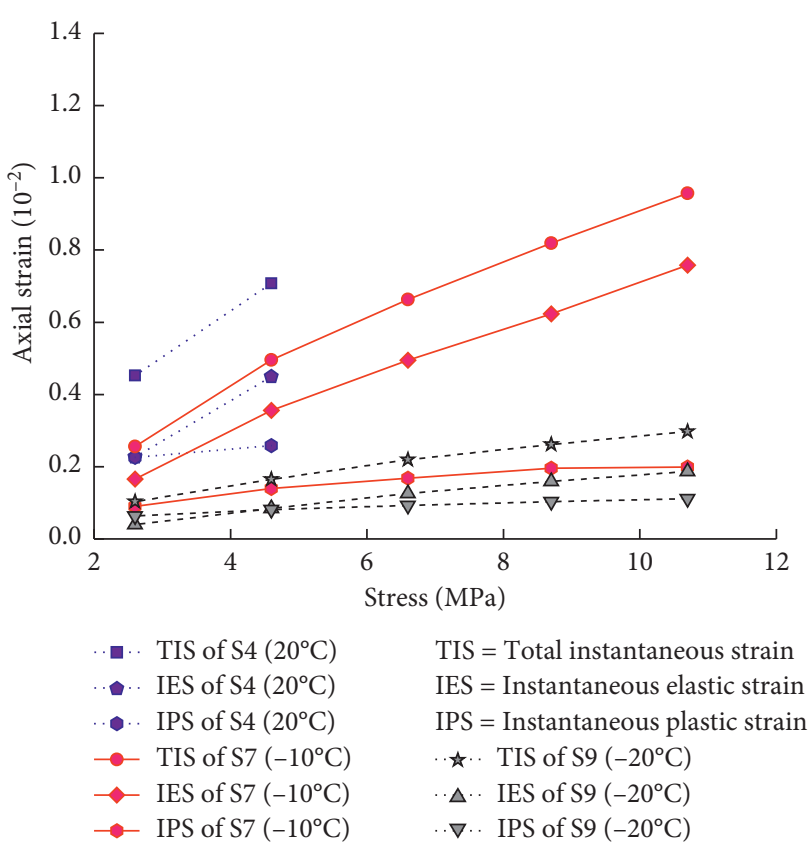

FIGURE 6: Instantaneous strain versus stress.

$-10^{\circ} \mathrm{C}$, and $-20^{\circ} \mathrm{C}$. It is evident that the instantaneous elastic strain and instantaneous plastic strain of the specimens increase as the stress level increases but decrease as the temperature decreases at the same stress level. This trend becomes more apparent with increasing stress levels. For example, when the stress level is $4.6 \mathrm{MPa}$, the instantaneous elastic strains of specimens S4, S7, and S9 are $4.49 \times 10^{-3}$, $3.56 \times 10^{-3}$, and $8.41 \times 10^{-4}$, respectively; reductions of $20.71 \%$ and $76.38 \%$ are reported for cold specimens S7 and S9, respectively. The instantaneous plastic strains are $2.58 \times 10^{-3}, 1.40 \times 10^{-3}$, and $8.09 \times 10^{-4}$ for specimens $\mathrm{S} 4, \mathrm{~S} 7$, and S9, respectively; reductions of $45.74 \%$ and $42.21 \%$ are reported for cold specimens S7 and S9, respectively. At a stress level of $8.7 \mathrm{MPa}$, the instantaneous elastic strains of specimens S7 and S9 (specimen S4 failed at this stress level) are $6.23 \times 10^{-3}$ and $1.59 \times 10^{-3}$, respectively; a reduction of $74.48 \%$ is reported for the cold specimen S9. The instantaneous plastic strains of specimens S7 and S9 are $1.96 \times 10^{-3}$ and $1.03 \times 10^{-3}$, respectively; a reduction of $47.45 \%$ is reported for the cold specimen S9. These results indicate that a decrease in temperature can effectively inhibit the instantaneous deformation of rocks.

Figure 6 shows that the curve of the stress-instantaneous-elastic-strain is almost linear; this indicates that the ratio of the stress increment to the instantaneous elastic strain increment at every stress level can be defined by the instantaneous elastic modulus $E_{\mathrm{me}}$ as follows:

$$
E_{\mathrm{me}}=\frac{\Delta \sigma}{\Delta \varepsilon_{\mathrm{me}}} .
$$

The instantaneous elastic moduli $E_{\text {me }}$ of red sandstone at different temperatures are presented in Figure 7. A certain degree of reduction is evident in the instantaneous elastic modulus at the second stress level, which can be caused by the compaction of fissures and closure of micropores at

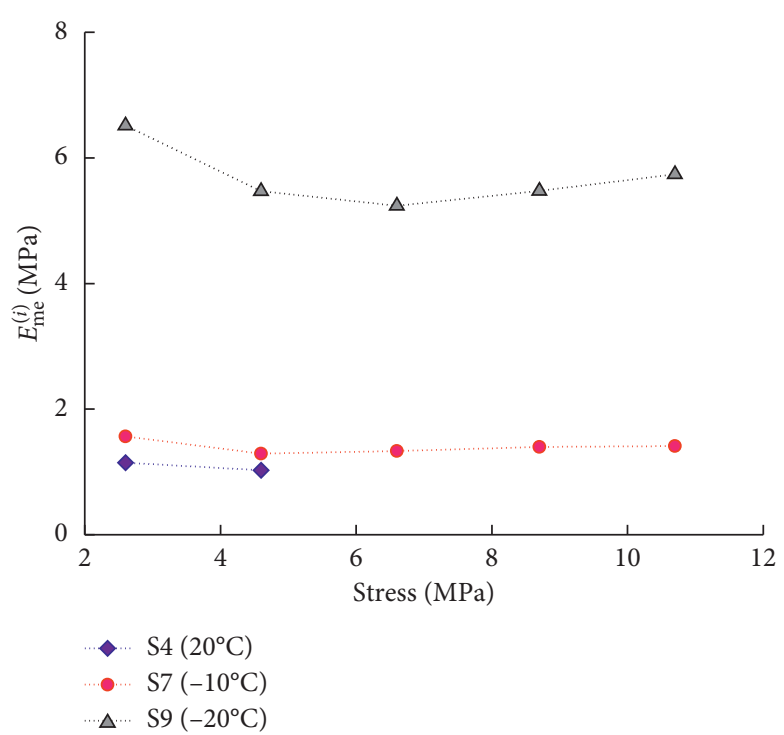

FIgURE 7: Instantaneous elastic modulus versus stress.

reduced stress levels. The elastic moduli increase at higher stress levels, thereby indicating that the specimens exhibit a tendency of strain hardening under low temperatures. Moreover, a decrease in temperature can significantly increase the instantaneous elastic modulus $E_{\text {me }}$ at the same stress level. For example, at the fourth stress level, the instantaneous elastic modulus $E_{\text {me }}$ of specimen S7 is $1.396 \mathrm{GPa}$, whereas that of specimen $\mathrm{S} 9$ is $5.475 \mathrm{GPa}$. This demonstrates that a decrease in temperature can effectively enhance the ability to resist instantaneous rock deformation.

4.2. Viscoelastic Strain and Viscoplastic Strain. The creep strain $\varepsilon_{\mathrm{c}}$ consists of viscoelastic strain $\varepsilon_{\mathrm{ce}}$ and viscoplastic strain $\varepsilon_{\mathrm{cp}}$. Figure 8 presents the relationship between the creep strain, viscoelastic strain, viscoplastic strain, and stress level of the red sandstone specimens at different temperatures. Figure 8 shows that the viscoelastic strain $\varepsilon_{\mathrm{ce}}$ and viscoplastic strain $\varepsilon_{\mathrm{cp}}$ of the specimens decrease as the temperature decreases at the same stress level. For example, the viscoelastic strains of specimens S7 and S9 (specimen S4 failed at this stress level) are $4.40 \times 10^{-4}$ and $2.24 \times 10^{-3}$, respectively, at the third stress level; a reduction of $49.09 \%$ is reported for the cold specimen S9. The viscoplastic strains are $6.1 \times 10^{-4}$ and $3.06 \times 10^{-3}$ for specimens S7 and S9; a reduction of $49.84 \%$ is reported for the cold specimen S9. The relationship between the temperature $T$ at the second stress level and the total creep strain $\varepsilon_{\text {tcs }}$ and viscoplastic strain $\varepsilon_{\mathrm{vps}}$ of the rock was fit as shown in Figure 9. The variation law of total creep strain and viscoplastic strain of rocks with a decrease in temperature was obtained. The fitting results were as follows:

$$
\begin{aligned}
& \varepsilon_{\mathrm{tcs}}=0.0423+0.0137 e^{T / 8.1280} \\
& \mathcal{E}_{\mathrm{vps}}=0.0022+0.0355 e^{T / 13.1896}
\end{aligned}
$$

It is clear that the total creep and viscoplastic strains of the rock are exponentially attenuated with decrease in 

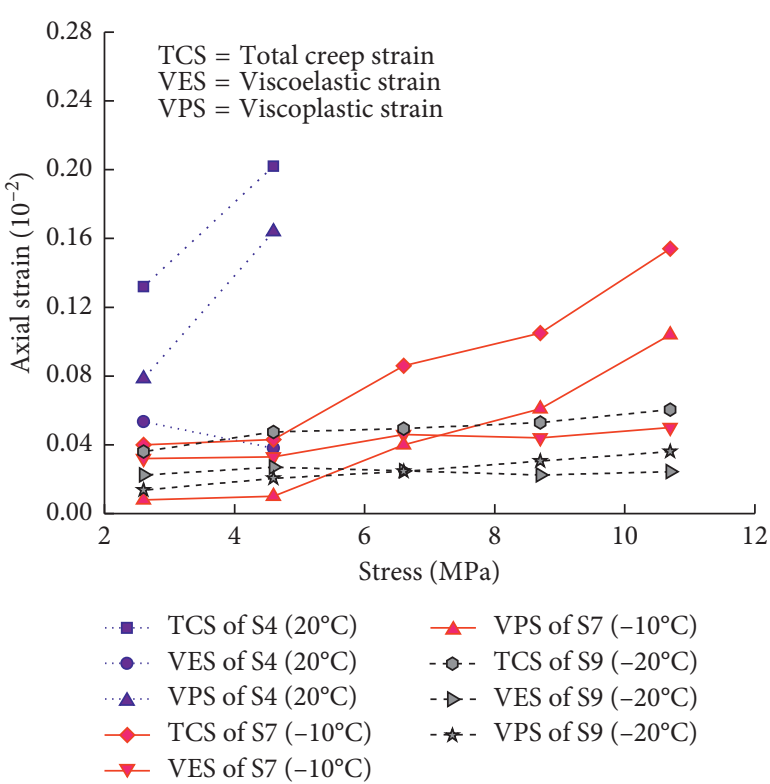

Figure 8: Total creep, viscoelastic strain, and viscoplastic strain versus stress.

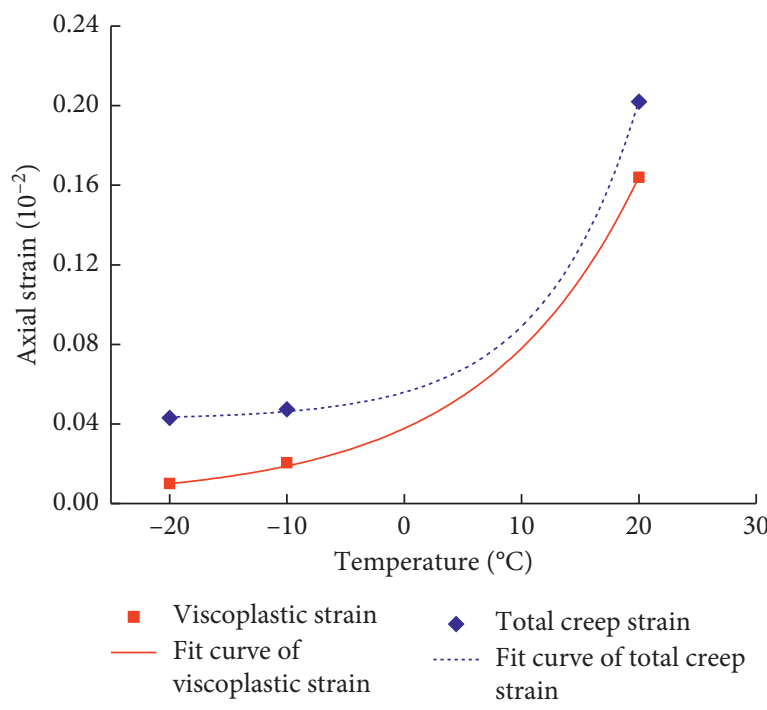

FIgURE 9: Total creep and viscoplastic strains versus temperature.

temperature. Figure 9 shows that $0^{\circ} \mathrm{C}$ is a critical point for the reduction of the total creep and viscoplastic strains of the rock with decrease in temperature. When the temperature is greater than $0^{\circ} \mathrm{C}$, the total creep and viscoplastic strains of the rock decrease rapidly and linearly with decrease in temperature. As the temperature approaches $0^{\circ} \mathrm{C}$, the slope of the curve decreases gradually, and the total creep strain and viscoplastic strain of the rock decrease as the temperature decreases. When the temperature is less than $0^{\circ} \mathrm{C}$, the total creep strain and viscoplastic strain of the rock continue to decrease as the temperature decreases; however, at the same temperature difference, the magnitude of decline is considerably less than that at temperatures greater than $0^{\circ} \mathrm{C}$, especially when the temperature is less than $-10^{\circ} \mathrm{C}$. This is because $0^{\circ} \mathrm{C}$ is the critical temperature at which water changes from the liquid state to the solid state. When the temperature is less than $0^{\circ} \mathrm{C}$, pore water inside the rock gradually changes from liquid to solid, thereby increasing the density of the internal structure of the rock and enhancing the resistance of the rock to deformation. As the temperature continues to decrease, the content of liquid water in the pores and thus the elastic modulus of the rock decreases gradually. Therefore, the magnitude of the total creep and viscoplastic strains of the rock decreases as the temperature decreases. These results demonstrate that a decrease in temperature can effectively inhibit the viscous deformation of the rock. Furthermore, the viscoplastic strain $\varepsilon_{\mathrm{cp}}$ increases with an increase in the stress level, and the proportion of viscoplastic strain in the total creep strain increases gradually. Consider the example of specimen S9. From the first to the fifth stress levels, the viscoplastic strain accounts for $37.95 \%, 43.25 \%, 49.60 \%$, $57.74 \%$, and $59.67 \%$ of the total creep strain, respectively. This demonstrates that the viscous fluidity of the rock increases with an increase in stress level. Moreover, the viscoplastic strain increases rapidly based on the cumulative effects of the stress history.

The viscoplastic strain accounts for a small proportion of the total creep strain at low stress levels, where the creep strain is largely composed of viscoelastic strain. As the stress level gradually increases, the creep strain of the rock exhibits both viscoelasticity and viscoplasticity. In the accelerated creep stage (rock specimens failed at this stress level), the viscoelastic and viscoplastic strains cannot be distinguished, thereby indicating that the creep strain is composed entirely of viscoplastic strain. The viscoplastic strain continues to increase with the accumulation of time and stress history until failure. The continuous development of viscoplastic strain is the main reason for creep failure in rock mass engineering [32].

4.3. Steady-State Creep-Strain Rate. In the steady-state creep stage, the creep-strain rate fluctuates within a certain range; however, it can be assumed that the creep rate is approximately constant. The average slope of the steady-state creep curve is shown as the steady-state creep-strain rate in Figure 10.

The steady-state creep rate decreases at the second stress level; then, it increases as the stress level increases. This is similar to the law of the instantaneous elastic modulus $E_{\mathrm{me}}$ in Figure 7. For the red sandstone specimens, there can be a state of "incomplete compaction" that indicates that there is a stress threshold value. When the stress level is less than the stress threshold, the microholes and cracks are not destroyed and deformation is not affected by the internal structure of the rock. When the stress level is greater than the stress threshold, cracks are compacted and microholes are destroyed and filled, thereby indicating that the ability of the rock to resist deformation improves. This can be the reason behind the decrease in instantaneous elastic modulus $E_{\text {me }}$ and steady-state creep rate at high stress levels. 


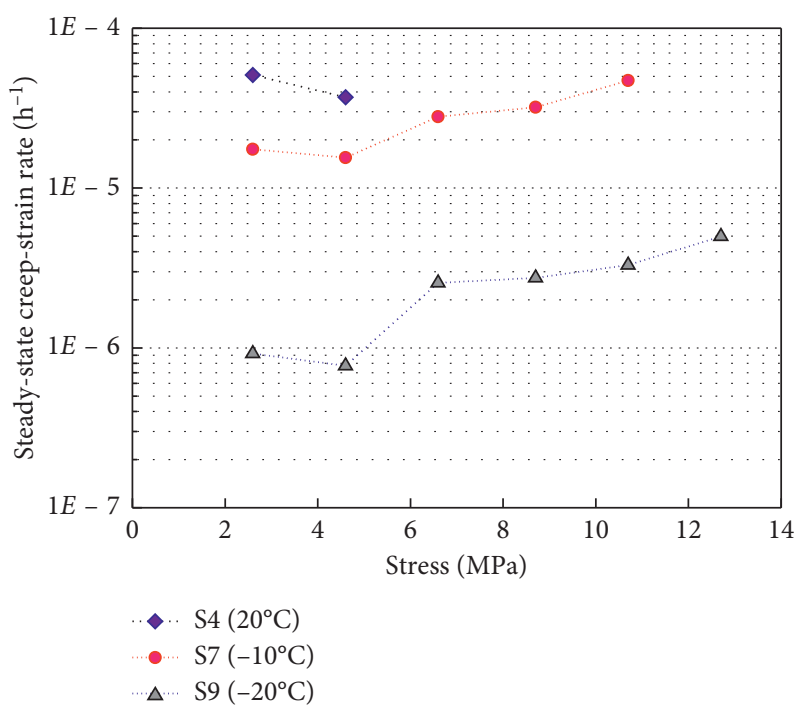

FIGURE 10: Steady-state creep-strain rate versus stress.

Furthermore, a decrease in temperature can reduce the steady-state creep rate of the rock specimens. Consider the fourth stress level as an example. The steady-state creep rate of specimen S7 is $3.20 \times 10^{-5} \cdot \mathrm{h}^{-1}$ and that of specimen S9 is $2.74 \times 10^{-6} \cdot \mathrm{h}^{-1}$; the former is 11.68 times greater than the latter. This indicates that a decrease in temperature can significantly reduce the creep rate of the rock, which is beneficial for the deformation control of the surrounding rock.

\subsection{Accelerated Creep Strain and Accelerated Creep-Strain} Rate. When loading to the third and sixth stress levels, specimens $\mathrm{S} 4\left(20^{\circ} \mathrm{C}\right)$ and $\mathrm{S} 7\left(-10^{\circ} \mathrm{C}\right)$ ruptured after entering the accelerated creep stage. Differential creep strain versus time curves were acquired for these specimens. The curves of the creep strain and creep-strain rate overtime at the final stress level are presented in Figures 10 and 11, respectively.

In Figure 11, the creep-strain rate of specimen S4 decreases from $1.693 \times 10^{-4} \cdot \mathrm{h}^{-1}$ to $0.125 \times 10^{-4} \cdot \mathrm{h}^{-1}$. The duration of $\mathrm{T}_{1}$ is approximately $0.2 \mathrm{~h}$ in zone $\mathrm{OA}$, which is known as the attenuation creep stage. In zone $\mathrm{AB}$, the creepstrain rate remains approximately constant at $0.125 \times 10^{-4} \cdot \mathrm{h}^{-1}$ and the creep curve increases linearly. The duration of $\mathrm{T}_{1} \mathrm{~T}_{2}$ is approximately $1.15 \mathrm{~h}$. This stage is identified as the steady-state creep stage. The creep-strain rate in zone $\mathrm{BC}$ increases rapidly to $0.46 \times 10^{-3} \cdot \mathrm{h}^{-1}$, which is the failure point. The duration of $\mathrm{T}_{2} \mathrm{~T}_{3}$ is approximately $0.07 \mathrm{~h}$, which is considered the accelerated creep stage.

Similarly, in Figure 12, the creep-strain rate of specimen S7 decreases from $1.517 \times 10^{-4} \cdot \mathrm{h}^{-1}$ to $0.104 \times 10^{-4} \cdot \mathrm{h}^{-1}$ in zone $\mathrm{OA}$. The duration of $T_{1}$ is approximately $0.16 \mathrm{~h}$, which represents the attenuation creep stage. The creep-strain rate in zone $\mathrm{AB}$ remains approximately constant at $0.104 \times 10^{-4} \cdot \mathrm{h}^{-1}$. The duration of $\mathrm{T}_{1} \mathrm{~T}_{2}$ is approximately $2.51 \mathrm{~h}$, which represents the steady-state creep stage. In zone $\mathrm{BC}$, the creep-strain rate increases rapidly to $0.30 \times 10^{-3} \cdot \mathrm{h}^{-1}$, which is the failure point. The duration of $\mathrm{T}_{2} \mathrm{~T}_{3}$ is $0.23 \mathrm{~h}$, which represents the accelerated creep stage.

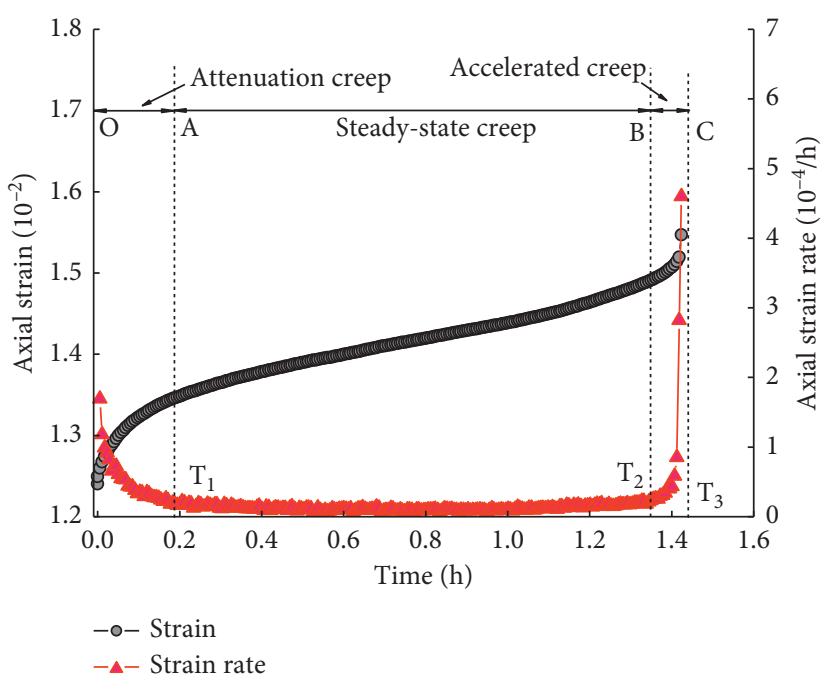

Figure 11: Creep-strain rate versus time (specimen $S 4,20^{\circ} \mathrm{C}$ ).

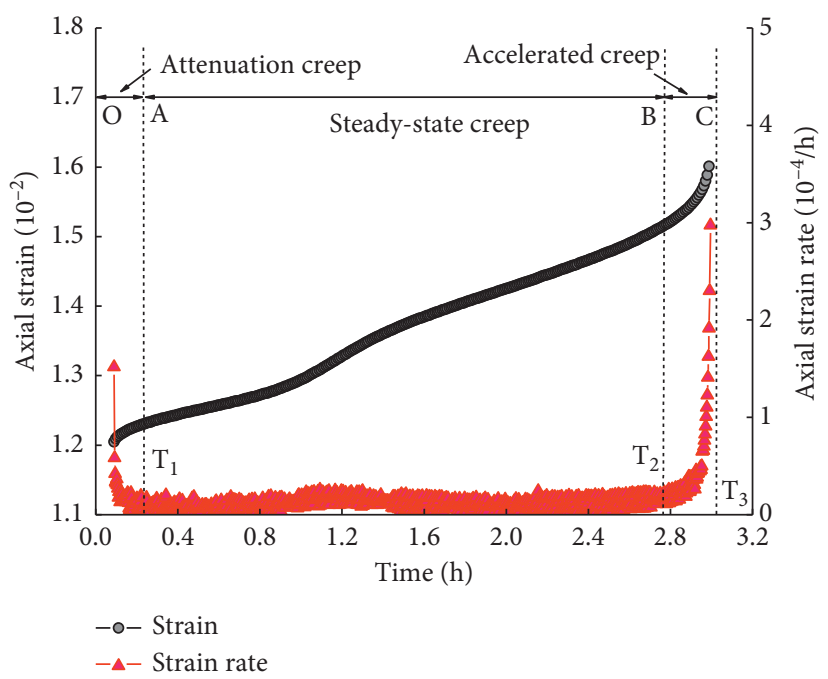

Figure 12: Creep-strain rate versus time (specimen $\mathrm{S} 7,-10^{\circ} \mathrm{C}$ ).

\section{Conclusions}

Based on uniaxial creep tests with multilevel loading and unloading cycles on red sandstone specimens at different temperatures $\left(20^{\circ} \mathrm{C},-10^{\circ} \mathrm{C}\right.$, and $\left.-20^{\circ} \mathrm{C}\right)$, the following conclusions can be drawn.

Low temperature has a significant effect on the deformation properties of red sandstone. The creep of the red sandstone exhibits typical three-stage behavior under different temperatures, and the total strain at each temperature can be categorized as instantaneous and creep strains, where the instantaneous strain includes the instantaneous elastic and plastic strains, and the creep strain includes the viscoelastic and viscoplastic strains.

As the temperature decreases, the instantaneous and creep deformations of the rock under different stress levels reduce gradually. The temperature decrease can effectively inhibit the viscous deformation of the rocks. The total creep strain and viscoplastic strain of the rocks are exponentially 
attenuated with decrease in temperature. $0^{\circ} \mathrm{C}$ is a critical point for the reduction of the total creep and viscoplastic strains of the rocks with decrease in temperature.

The stress level required for the accelerated creep stage of the rocks increases with decrease in temperature; hence, the creep failure stress of the rock increases with decrease in temperature.

The steady-state creep rate of the rock samples decreases with decrease in temperature, whereas the duration of the creep increases with decrease in temperature, especially in the case of the accelerated creep stage.

\section{Data Availability}

The data used to support the findings of this study are included within the article (displayed through figures and tables).

\section{Conflicts of Interest}

The authors declare that they have no conflicts of interest.

\section{Acknowledgments}

This work was supported by the National Natural Science Foundation of China (11972283 and 11872299) and the Natural Science Foundation of Shaanxi Province, China (2017JM1039). The authors are grateful for the generous support.

\section{References}

[1] X. Tan, W. Chen, H. Liu, L. Wang, W. Ma, and A. H. C. Chan, "A unified model for frost heave pressure in the rock with a penny-shaped fracture during freezing," Cold Regions Science and Technology, vol. 153, pp. 1-9, 2018.

[2] Y. Inada and K. Yokota, "Some studies of low temperature rock strength," International Journal of Rock Mechanics and Mining Sciences \& Geomechanics Abstracts, vol. 21, no. 3, pp. 145-153, 1984.

[3] K. Aoki, K. Hibiya, and T. Yoshida, "Storage of refrigerated liquefied gases in rock caverns: characteristics of rock under very low temperatures," Tunnelling and Underground Space Technology, vol. 5, no. 4, pp. 319-325, 1990.

[4] T. Yamabe and K. M. Neaupane, "Determination of some thermo-mechanical properties of Sirahama sandstone under subzero temperature condition," International Journal of Rock Mechanics and Mining Sciences, vol. 38, no. 7, pp. 1029-1034, 2001.

[5] L. Jiang, Y. Cheng, Z. Han et al., "Effect of frost heave on internal structure and mechanical behavior of rock mass at low temperature," Journal of Applied Science and Engineering,", vol. 21, no. 4, pp. 527-539, 2018.

[6] C. Park, J. H. Synn, H. S. Shin, D. S. Cheon, H. D. Lim, and S. W. Jeon, "Experimental study on the thermal characteristics of rock at low temperatures," International Journal of Rock Mechanics and Mining Sciences, vol. 41, no. 3, pp. 81-86, 2004.

[7] G. M. Xu, Q. S. Liu, W. W. Peng, and X. X. Chang, "Experimental study on basic mechanical behaviors of rocks under low temperatures," Chinese Journal of Rock Mechanics and Engineering, vol. 25, no. 12, pp. 2502-2508, 2006.
[8] M. M. Tang, Z. Y. Wang, Y. L. Sun, and J. H. Ba, "Experimental study of mechanical properties of granite under low temperature," Chinese Journal of Rock Mechanics and Engineering, vol. 29, no. 4, pp. 787-794, 2010.

[9] J. M. Xi, G. S. Yang, L. Pang, X. T. Lu, and F. L. Liu, "Experimental study on basic mechanical behaviors of sandy mudstone under low freezing temperature," Journal of China Coal Society, vol. 39, no. 7, pp. 1262-1268, 2014.

[10] Y. Zhao, L. Zhang, W. Wang, W. Wan, and W. Ma, "Separation of elastoviscoplastic strains of rock and a nonlinear creep model," International Journal of Geomechanics, vol. 18, no. 1, pp. 1-18, 2018.

[11] Y. Zhao, Y. Wang, W. Wang, W. Wan, and J. Tang, "Modeling of non-linear rheological behavior of hard rock using triaxial rheological experiment," International Journal of Rock Mechanics and Mining Sciences, vol. 93, pp. 66-75, 2017.

[12] E. Maranini and M. Brignoli, "Creep behaviour of a weak rock: experimental characterization," International Journal of Rock Mechanics and Mining Sciences, vol. 36, no. 1, pp. 127-138, 1999.

[13] D. F. Malan, "Simulating the time-dependent behaviour of excavations in hard rock," Rock Mechanics and Rock Engineering, vol. 35, no. 4, pp. 225-254, 2002.

[14] S. Yang and Y. Jiang, "Triaxial mechanical creep behavior of sandstone," Mining Science and Technology (China), vol. 20, no. 3, pp. 339-349, 2010.

[15] G. Wang, L. Zhang, Y. Zhang, and G. Ding, "Experimental investigations of the creep-damage-rupture behaviour of rock salt," International Journal of Rock Mechanics and Mining Sciences, vol. 66, pp. 181-187, 2014.

[16] C. Ping, Y. Wen, Y. Wang, H. Yuan, and B. Yuan, "Study on nonlinear damage creep constitutive model for high-stress soft rock," Environmental Earth Sciences, vol. 75, no. 10, pp. 1-8, 2016.

[17] W. Yang, R. Gamage, C. Huang, G. Luo, J. Guo, and S. Wang, "Loading history effect on creep deformation of rock," Energies, vol. 11, no. 6, pp. 2-19, 2018.

[18] H. Mansouri and R. Ajalloeian, "Mechanical behavior of salt rock under uniaxial compression and creep tests," International Journal of Rock Mechanics and Mining Sciences, vol. 110, pp. 19-27, 2018.

[19] R. Hou, K. Zhang, J. Tao, X. Xue, and Y. Chen, “A nonlinear creep damage coupled model for rock considering the effect of initial damage," Rock Mechanics and Rock Engineering, vol. 52, no. 5, pp. 1275-1285, 2019.

[20] F. Wu, J. Chen, and Q. Zou, “A nonlinear creep damage model for salt rock," International Journal of Damage Mechanics, vol. 28, no. 5, pp. 758-771, 2019.

[21] L. Chen, J. Liu, C. Wang, J. Liu, and J. Wang, “Experimental investigation on the creep behaviour of beishan granite under different temperature and stress conditions," European Journal of Environmental and Civil Engineering, vol. 19, no. 1, pp. s43-s53, 2015.

[22] L. Chen, C. P. Wang, J. F. Liu, Y. Li, J. Liu, and J. Wang, "Effects of temperature and stress on the time-dependent behavior of Beishan granite," International Journal of Rock Mechanics and Mining Sciences, vol. 93, pp. 316-323, 2017.

[23] M. J. Heap, P. Baud, and P. G. Meredith, "Influence of temperature on brittle creep in sandstones," Geophysical Research Letters, vol. 36, no. 19, pp. 1-6, 2009.

[24] Y. Lu and L. Wang, "Effect of water and temperature on shortterm and creep mechanical behaviors of coal measures mudstone," Environmental Earth Sciences, vol. 76, no. 17, pp. 1-15, 2017. 
[25] E. Rybacki, J. Herrmann, R. Wirth, and G. Dresen, "Creep of posidonia shale at elevated pressure and temperature," Rock Mechanics and Rock Engineering, vol. 50, no. 12, pp. 31213140, 2017.

[26] J. M. Wang, Z. C. Feng, Y. S. Zhao, and B. P. Xi, “A study on creep analytical solution and creep parameters of granite drilling in steady state under high temperature and high pressure," Materials Research Innovations, vol. 19, no. 5, pp. 380-384, 2015.

[27] D. W. Li, R. H. Wang, and J. H. Fan, "Nonlinear rheological model for frozen soft rock during Cretaceous period," Chinese Journal of Geotechnical Engineering, vol. 33, no. 3, pp. 398403, 2011.

[28] R. Shan, L. Song, D. Li, B. Huang, N. Liu, and W. Zhao, "Study of nonlinear creep model of frozen red sandstone," Rock and Soil Mechanics, vol. 35, no. 6, pp. 1541-1546, 2014.

[29] R. Shan, B. Yao, P. Sun, S. Sui, Y. Huang, and J. Chen, "Study of triaxial creep mechanical properties and constitutive model of frozen stratified red sandstone," Journal of China University of Mining and Technology, vol. 48, no. 1, 2019.

[30] C. C. Xia and S. Y. Zhong, "Experimental data processing method in consideration of influence of loading history on rock specimen deformation," Journal of Central-South Institute of Mining and Metallurgy, vol. 20, no. 1, pp. 18-24, 1989.

[31] Y. Zhao, L. Zhang, W. Wang et al., "Creep behavior of intact and cracked limestone under multi-level loading and unloading cycles," Rock Mechanics and Rock Engineering, vol. 50, no. 6, pp. 1409-1424, 2017.

[32] D. Sterpi and G. Gioda, "Visco-plastic behaviour around advancing tunnels in squeezing rock," Rock Mechanics and Rock Engineering, vol. 42, no. 2, pp. 319-339, 2009. 


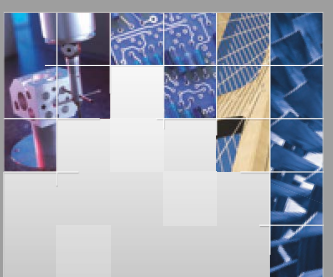

\section{Enfincering}
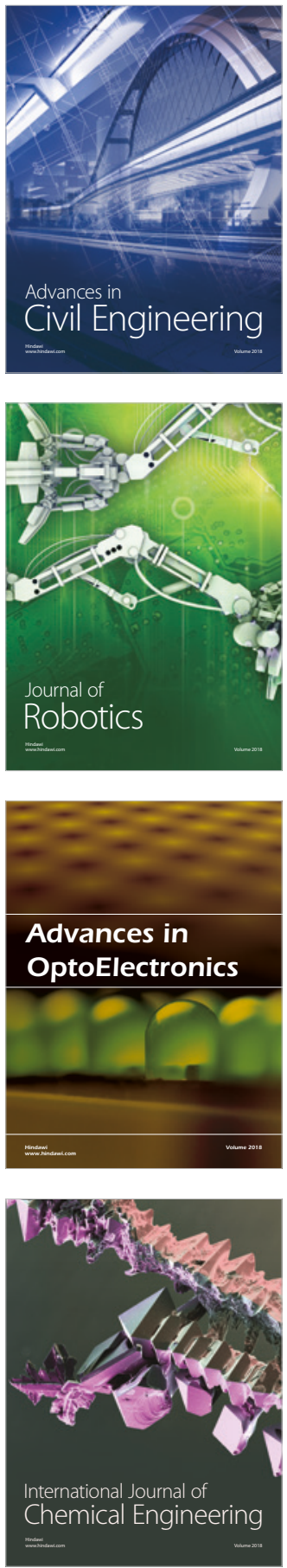

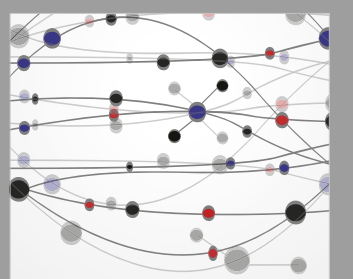

\section{Rotating \\ Machinery}

The Scientific World Journal

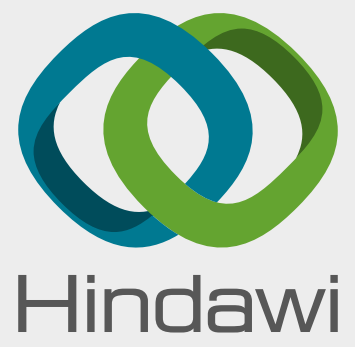

Submit your manuscripts at

www.hindawi.com
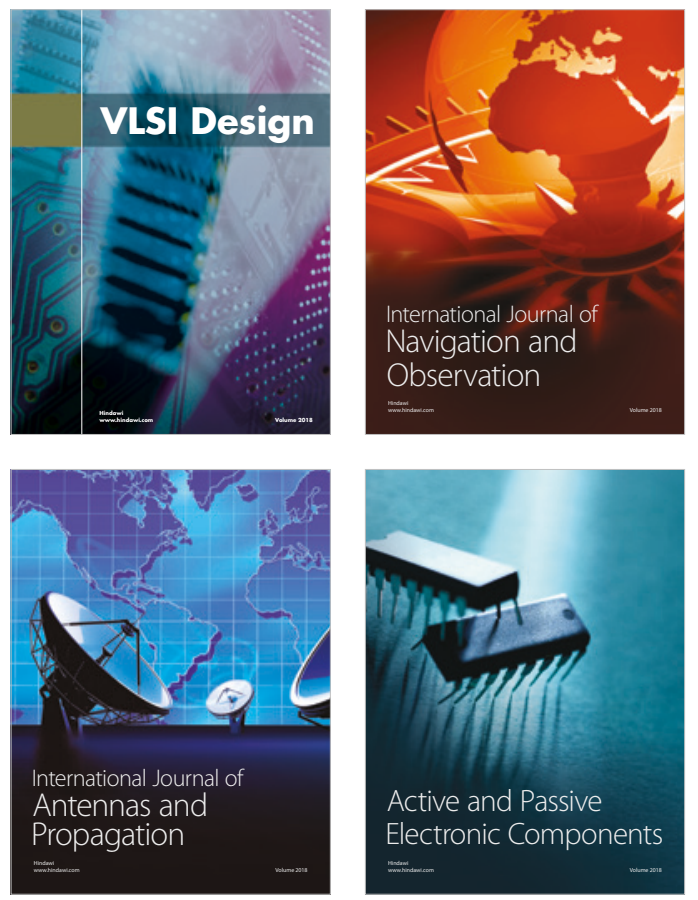
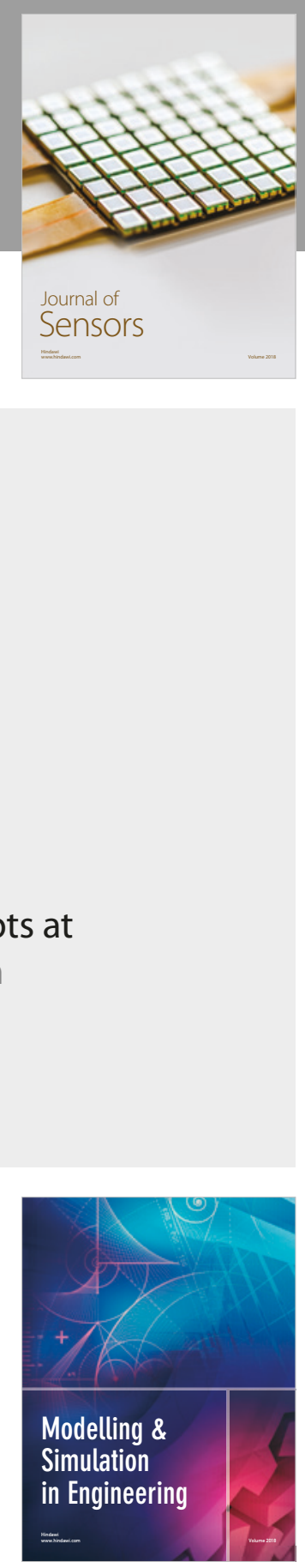

\section{Advances \\ Multimedia}
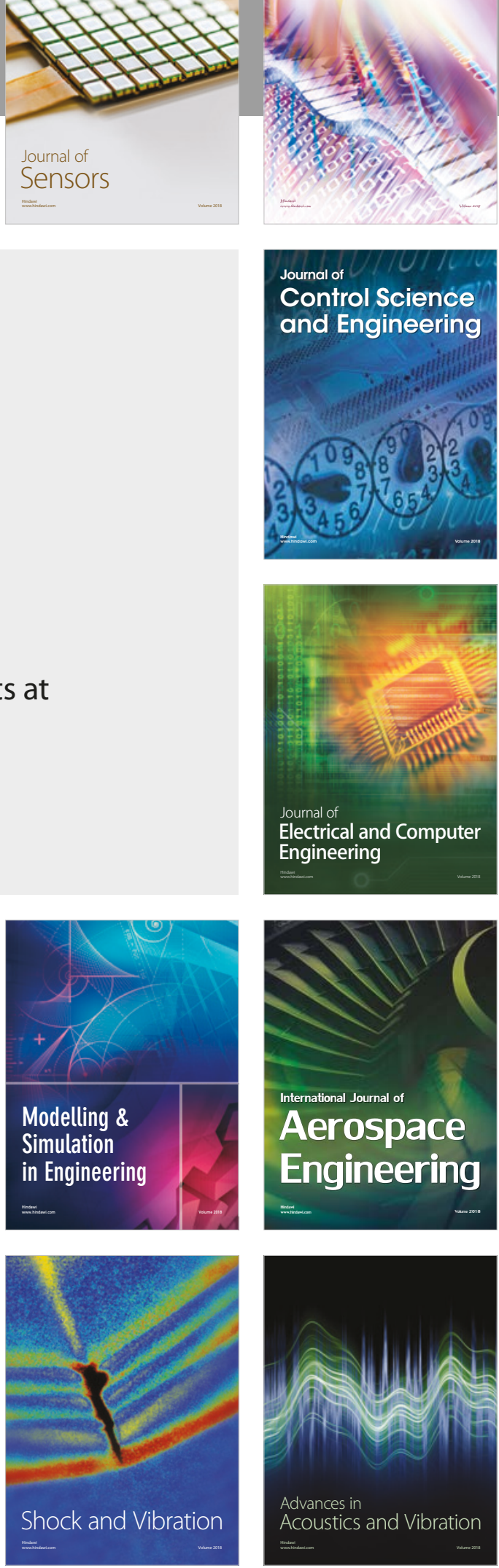